\title{
EVALUATION OF CHOROID THICKNESS CHANGES AFTER UNEVENTFUL PHACOEMULSIFICATION SURGERY USING SPECTRAL DOMAIN OPTICAL COHERENCE TOMOGRAPHY AT A TERTIARY CARE EYE HOSPITAL
}

\author{
Aisha Rafique, Omar Zafar, Summaya Khan, Hassaan Javaid \\ Armed Forces Institute of Ophthalmology/National University of Medical Sciences (NUMS) Rawalpindi Pakistan
}

\begin{abstract}
Objective: To analyze the effects of uneventful phacoemulsification surgery on choroidal thickness using spectral domain optical coherence tomography.

Study Design: Prospective comparative study.

Place and Duration of Study: Armed Forces Institute of Ophthalmology, Rawalpindi, from Jun 2018 to Jun 2019.

Methodology: In this prospective study, 300 eyes of 300 patients undergoing phacoemulsification surgery were included. All patients underwent detailed ophthalmologic examination, including measurement with optical biometry, intraocular pressure and choroid thickness. The choroidal thickness was measured perpendicularly at the fovea using spectral domain optical coherence tomography preoperatively and 1 month postoperatively. Changes in intraocular pressure and choroid thickness after surgery were evaluated.

Results: There was a statistically significant increase in the choroid thickness in early postoperative period $(p$-value $<0.01)$. This increment was prominent in sub foveal regions. The intraocular pressure decreased significantly 1 month after surgery ( $p$-value <0.01). The change in intraocular pressure was correlated with the choroid thickness change at sub foveal region.

Conclusion: Uncomplicated phacoemulsification induces non-pathologic increase in sub-foveal choroid thickness probably due to the inflammatory insult of the surgery. Long-term follow-up of eyes having phacoemulsification surgery may provide further insight into the effects of cataract surgery on the choroid.
\end{abstract}

Keywords: Optical coherence tomography, Phacoemulsification, Sub-foveal choroidal thickness.

How to Cite This Article: Rafique A, Zafar O, Khan S, Javaid H. Evaluation of Choroid Thickness Changes After Uneventful Phacoemulsification Surgery Using Spectral Domain Optical Coherence Tomography at A Tertiary Care Eye Hospital. Pak Armed Forces Med J 2021; 71(6): 2202-2206. Doi: https://doi.org/10.51253/pafmj.v71i6.4042

This is an Open Access article distributed under the terms of the Creative Commons Attribution License (https://creativecommons.org/licenses/by-nc/4.0/), which permits unrestricted use, distribution, and reproduction in any medium, provided the original work is properly cited.

\section{INTRODUCTION}

Choroid is highly vascular structure lying between retinal pigment epithelium and lamina fusca of sclera, supplying blood to outer retinal layers. It plays an important role in various vision deteriorating diseases such as age related macular degeneration, choroidal neo-vascularization, central serous chorioretinopathy and chorioretinal atrophy in high myopia. ${ }^{1,2}$ Choroidal thickness is determined by amount of vascularization and varies by age, sex, refractive state of eye along with any previous history of ocular trauma or surgery like cataract extraction. ${ }^{3-5}$ Phacoemulsification is most common invasive intraocular surgery for removal of cataract and improves visual outcome markedly. In this procedure, opaque crystalline ocular lens is emulsified with an ultrasonic hand piece, aspirated from eye, and replaced by intra ocular lens implant. ${ }^{6}$ It is otherwise a safe procedure but it is associated with complications if coexistent with diabetic retinopathy, chorioretinal atrophy and can cause pseudophakic

Correspondence: Dr Aisha Rafique, Department of Ophthalmology, Armed Forces Institute of Ophthalmology, Rawalpindi Pakistan Received: 27 Mar 2020; revision received: 01 Jun 2020; accepted: 02 Jun 2020 cystoid macular edema (Irvine-Gass-syndrome). ${ }^{7}$ These complications are speculated to be induced due to inflammatory reactions, increased free radicals formation leading to release of growth factors and prostaglandins leading an increase in choroid thickness observed after phacoemulsification. 8,9

Previously, measurement of choroid thickness was restricted to ultrasonography. Currently, optical coherence tomography has steadily evolved into an integral element in diagnosis and progression of retinal and choroidal disease. It provides cross sectional images of chorioretinal morphology and quantification of disease effects in the form of thickness maps. A recent advance in optical coherence tomography technology, spectral domain optical coherence tomography (SDOCT) has significantly increased scanning speeds (more than 100 folds). ${ }^{10}$ Fast acquisition speed and higher resolution images of SD-OCT provide useful information of choroidal thickness. It obtains sub-surface images of translucent materials based on low coherence interferometry, characteristically employing near infrared light. This longer wavelength light penetrates into scattering medium of choroid and achieves its 
sub-micrometer resolution. Post-operative choroidal thickness measurement will aid in understanding pathogenesis of retinal and choroidal changes leading to pseudophakic cystoid macular edema. This edema compromise the vision and affects patient satisfaction of not re gaining visual acuity even after surgery.

\section{METHODOLOGY}

This prospective comparative study was started after taking approval by ethical committee of Armed Forces Institute of Ophthalmology (AFIO), Rawalpindi (reference number 231/ERC/AFIO), from June 2018 to June 2019.

Inclusion Criteria: The patients visiting cataract clinic with visually significant lenticular opacity were included.

Exclusion Criteria: Patients with co-existent systemic diseases, or having other ocular diseases including uveitis, glaucoma, retinal detachment, retinal vascular occlusive disease, retinal inflammatory diseases, secondary complicated cataract and eyes with previous ocular surgeries or patients unable to sit upright were excluded from the study.

Patients were briefly described about the procedure. Informed consent was taken from all patients who agreed to participate in the study. A total of 300 patients were included in the study using non-probability consecutive sampling technique. The sample size was calculated by using WHO sample size calculator keeping 95\% confidence interval and 5\% error. ${ }^{11}$ All enrolled patients had age related cataract as only ocular disease. Patients underwent uncomplicated phacoemulsification by same surgeon.

Lens Opacities Classification System (LOCS III) staging was used to standardize cataract hardness of patients. ${ }^{12}$ Severe dense brown cataract that might have caused unreliable SD-OCT measurement because of reduced penetration and poor fixation were not included in study.

Phacoemulsification (Centurion vision system, Alcon Laboratories, USA) was performed. About 2.8 $\mathrm{mm}$ superotemporal triplanar clear corneal incision was made in all surgeries. Hydrophobic Acrylic Intra Ocular Lens (AcrySoft IQ, Alcon laboratories, USA) was implanted in all enrolled patients. Patients were advised topical Moxifloxacin, topical prednisolone and topical Nepafenac eye drops for six weeks post operatively.

Pre-operatively all enrolled patients underwent detailed ophthalmic examination along with fundo- scopy after pupillary dilation. It included visual acuity measurement, best corrected visual acuity, anterior segment bio-microscopy, intraocular pressure measurement. Axial length and intra ocular lens power was measured by optical biometry (IOL Master 700, Zeiss, Jena, Germany) in all cases. Choroid thickness measurement using SD-OCT were taken between 9:00 am and 12:00 am to avoid effects of diurnal fluctuations. Intraocular pressure was measured using Goldman Applanation Tonometer pre-operatively and 4 weeks post operatively. Intraocular pressure measurement was performed after SD-OCT imaging as applanation by GAT may cause inadvertent transient corneal edema.

Enhanced Depth Imaging-Optical Coherence Tomography (EDI-OCT) with Spectralis OCT (Heidelberg Engineering, USA) was used to image choroid and measure its thickness. EDI-OCT B-Scans average 100 times, centered on fovea were obtained for each patient pre-operatively and these scans were marked as patient's baseline scans. These baseline scans were used as reference for subsequent scans using option of "following up" in Spectralis Heidelberg software with the patient in same position. These scans were repeated four weeks post operatively after phacoemulsification.

Measurement of choroidal thickness was performed manually using "measuring calipers" centered on fovea provided by Spectralis Heidelberg software. Thickness of choroid was measured by sections passing through fovea vertically. Choroidal margins were considered as the distance between outer edge of hyper reflective retinal pigment epithelium and internal margin of choroidal scleral junction (Figure). Images with good signal strength were taken.

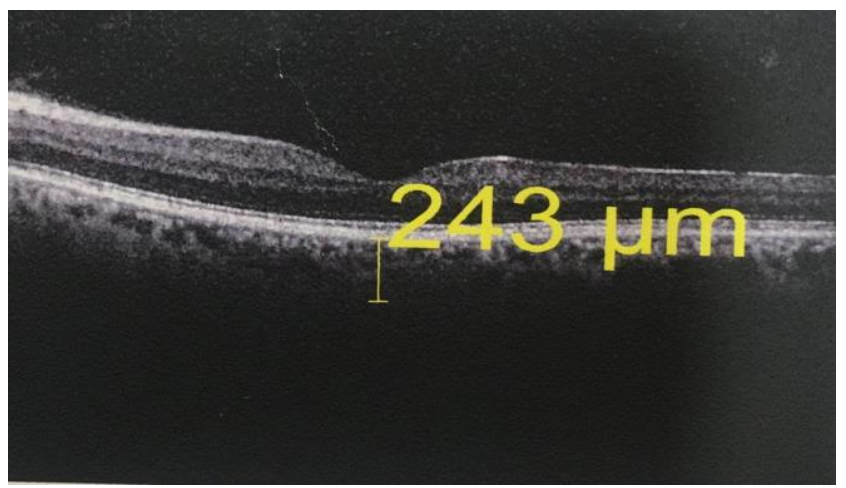

Figure: Measuring of choroidal thickness using manual calipers.

The surgical procedure was similar for all enrolled patients. Cataract surgery was performed by 
phacoemulsification. Intraocular lens were implanted in capsular bag. There were no complications during surgeries. Time elapsed between corneal incisions till stromal hydration was considered as surgical time. Post operatively, all patients were advised Moxifloxacin eye drops four hourly initially for two weeks followed by six hourly for another six weeks. Topical non-steroidal anti-inflammatory eye drops were prescribed twice daily for four weeks and topical prednisolone was advised four hourly for initial two weeks and then six hourly for another four weeks.

Data was analyzed by using Statistical Package for the social sciences (SPSS) version 23. Descriptive statistics were used to calculate mean with standard deviation for quantitative data and frequency and percentages for qualitative data. Paired-samples $t$-test was used for comparison between means of preoperative and postoperative of sub foveal choroidal thickness measurements. Evaluation was made at a $95 \%$ confidence interval, and the $p$-value of $\leq 0.05$ was considered statistically significant.

\section{RESULTS}

In this study a total of 300 patients were enrolled. The mean age of the patients was $65.06 \pm 5.70$ years. Majority $180(60 \%)$ of the patients had age more than 65 years and $120(40 \%)$ patients were younger than 65 years. Main bulk 222 (74\%) of the patients in our study sample were males and $78(26 \%)$ were females. Cataract severity was classified as per Lens Opacification Classification system (LOCS). LOCS I being mild and LOCS IV being dense cataract and affecting vision markedly. Out of 300 patients, 96 (32\%) and 198 (66\%) had cataract severity falling into LOCS II and LOCS III respectively. Only $6(2 \%)$ patients had cataract severity of LOCS IV. Mean surgical time was $15.62 \pm 1.28$ minutes. Descriptive statistics of patient characteristics given at Table-I. The statistically significant ( $p$-value $<0.01)$ increase in choroid thickness was noted after

Table-I: Descriptive statistics of patient characteristics.

\begin{tabular}{l|c}
\hline Characteristics & $\mathbf{n}(\%)$ \\
\hline Age of Patients (Mean \pm SD) $65.06 \pm 5.70$ & Years \\
\hline$\leq 65$ years & $120(40)$ \\
\hline$>65$ years & $180(60)$ \\
\hline Gender of Patients & $222(74)$ \\
\hline Male & $78(26)$ \\
\hline Female & \\
\hline $\begin{array}{l}\text { Cataract Severity on Basis of Lens Opacification Classification } \\
\text { System (LOCS) }\end{array}$ \\
\hline LOCS - I & - \\
\hline LOCS - II & $96(32)$ \\
\hline LOCS - III & $198(66)$ \\
\hline LOCS - IV & $6(2)$ \\
\hline Mean Surgical Time (Mean \pm SD) $15.62 \pm 1.28$ minutes \\
\hline
\end{tabular}

surgery in sub-foveal regions. However, intraocular pressure significantly decreased $(p$-value $<0.01)$ in early post-operative period than preoperatively. Detailed comparison of sub foveal choroid thickness and intraocular pressure is given at Table-II.

Table-II: Comparison of sub foveal choroid thickness and intraocular pressure in the study groups.

\begin{tabular}{|c|c|c|c|}
\hline Parameters & Categories & Mean \pm SD & $\begin{array}{c}p- \\
\text { value }\end{array}$ \\
\hline \multicolumn{4}{|l|}{ Overall Comparison } \\
\hline \multirow{2}{*}{$\begin{array}{l}\text { Sub Foveal Choroid } \\
\text { Thickness }(\mu \mathrm{m})\end{array}$} & Pre-Operatively & $233.46 \pm 9.52$ & \multirow[b]{2}{*}{$<0.01$} \\
\hline & $\begin{array}{c}\text { Four Weeks Post- } \\
\text { Operatively }\end{array}$ & $276.80 \pm 16.75$ & \\
\hline \multirow{2}{*}{$\begin{array}{l}\text { Intraocular Pressure } \\
(\mathrm{mm} \text { of } \mathrm{Hg})\end{array}$} & Pre-Operatively & $18.64 \pm 3.17$ & \multirow[b]{2}{*}{$<0.01$} \\
\hline & $\begin{array}{c}\text { Four Weeks Post- } \\
\text { Operatively }\end{array}$ & $16.56 \pm 2.97$ & \\
\hline \multicolumn{4}{|c|}{ Gender of the Patients } \\
\hline \multirow{2}{*}{$\begin{array}{l}\text { Sub Foveal Choroid } \\
\text { Thickness (Pre - } \\
\text { Operative) }\end{array}$} & Male & $233.40 \pm 9.82$ & \multirow[b]{2}{*}{$<0.01$} \\
\hline & Female & $233.61 \pm 8.65$ & \\
\hline \multirow{2}{*}{$\begin{array}{l}\text { Sub Foveal Choroid } \\
\text { Thickness (4 Weeks } \\
\text { Post-Operative) }\end{array}$} & Male & $276.16 \pm 17.12$ & \multirow[b]{2}{*}{$<0.01$} \\
\hline & Female & $278.61 \pm 15.62$ & \\
\hline \multirow{2}{*}{$\begin{array}{l}\text { Intraocular Pressure } \\
\text { (Pre-Operative) }\end{array}$} & Male & $18.67 \pm 3.13$ & \multirow{2}{*}{$<0.01$} \\
\hline & Female & $18.53 \pm 3.31$ & \\
\hline \multirow{2}{*}{$\begin{array}{l}\text { Intraocular Pressure } \\
\text { (4 Weeks Post- } \\
\text { Operative) }\end{array}$} & Male & $16.54 \pm 2.92$ & \multirow[b]{2}{*}{$<0.01$} \\
\hline & Female & $16.61 \pm 3.14$ & \\
\hline \multicolumn{4}{|l|}{ Age Groups of Patients } \\
\hline \multirow{2}{*}{$\begin{array}{l}\text { Sub Foveal Choroid } \\
\text { Thickness (Pre - } \\
\text { Operative) }\end{array}$} & $\leq 65$ & $228.25 \pm 8.74$ & \multirow[b]{2}{*}{$<0.01$} \\
\hline & $>65$ & $236.93 \pm 8.37$ & \\
\hline \multirow{2}{*}{$\begin{array}{l}\text { Sub Foveal Choroid } \\
\text { Thickness (4 Weeks } \\
\text { Post-Operative) }\end{array}$} & $\leq 65$ & $267.35 \pm 17.29$ & \multirow[b]{2}{*}{$<0.01$} \\
\hline & $>65$ & $283.10 \pm 13.05$ & \\
\hline \multirow{2}{*}{$\begin{array}{l}\text { Intraocular Pressure } \\
\text { (Pre-Operative) }\end{array}$} & $\leq 65$ & $18.15 \pm 2.94$ & \multirow{2}{*}{$<0.01$} \\
\hline & $>65$ & $18.96 \pm 3.29$ & \\
\hline \multirow{2}{*}{$\begin{array}{l}\text { Intraocular Pressure } \\
\text { (4 Weeks Post- } \\
\text { Operative) }\end{array}$} & $\leq 65$ & $16.30 \pm 2.92$ & \multirow[b]{2}{*}{$<0.01$} \\
\hline & $>65$ & $16.73 \pm 3.00$ & \\
\hline
\end{tabular}

\section{DISCUSSION}

After phacoemulsification, there was no change in fundoscopic appearance clinically but sub-clinical changes, as indicated by SD-OCT sectioning have been reported in most of eyes undergoing cataract surgery. ${ }^{13}$ Cataract surgery, although anterior segment procedure is capable of affecting posterior segment especially in Diabetic retinopathy and Irvine-Gass Syndrome (pseudophakic cystoid macular edema). ${ }^{14}$ Dense scanning afforded by SD-OCT allows identification of such retinochoroidal vascular and morphological patterns.

The results of our study are comparable to most of international studies. Ibrahim et al concluded that mean SFCT after cataract surgery increased to up to three months duration. ${ }^{15}$ However, in our study choroid thickness was evaluated in early postoperative 
period. A meta-analysis conducted by Zeng et al, on changes in SFCT after cataract surgery concluded SFCT increased after cataract surgery and this increase lasted for at least 3 months. Asians and patients without NSAIDs in postoperative period were more likely to have a thicker SFCT after cataract surgery thus implying role of post-operative inflammation. ${ }^{16}$ Another study conducted by Morrin et al, inferred that SFCT increased after cataract surgery and presence of a diabetic retinopathy is critical for evaluation of choroidal thickness as increase in thickness was more marked in eyes of diabetic patients. ${ }^{17}$

Anti-inflammatory therapy is part of our standard post-operative protocol, advised to all our patients for six weeks after surgery. So in this study the actual postoperative choroidal response was evaluated. These anti-inflammatory therapies are known to reduce post-operative inflammations of choroid and retina.

It is suggested that increased in choroidal thickness after surgery is the effect of pro inflammatory cytokines and prostaglandins that are believed to be raised. Surgical trauma to eye impairs blood aqueous barrier leading to accumulation of inflammatory mediators i.e. immune complexes, cytokine and prostaglandins. These inflammatory mediators pass from anterior chamber, vitreous to retina and choroid leading to impairment of inner and outer blood retinal barrier causing an inflammatory cascade. ${ }^{18,19}$

Another mechanism suggested for post-surgical inflammation is increased gene expression that simultaneously induces inflammatory response in all ocular layers. In a mouse model cataract surgery increased protein secretion in the retina and choroid due to expression of pro inflammatory gene related to chemokines such as CCL-2 and SDF-1, both of which can impair the blood-retinal barrier. ${ }^{20}$

Another animal study concluded marked upregulation of IL-1 B, an inflammatory mediator in neurosensory retina, RPE and choroid. A similar response in human eye might explain mechanism of cataract surgery associated inflammation of retina and choroid as evident by raised thickness in our study. ${ }^{21}$

It has been observed that even uncomplicated cataract surgery causes temporary thickening of the retina especially macular area. Factors attributed include high ultrasound power used during procedure, use of ophthalmic visco surgical devices and intraoperative photostress due to microscope light. ${ }^{22}$
In our data cataract, hardness of patients ranged from Grade II to Grade IV based on LOCS III. Dense cataracts were excluded as they prevent reliable OCT Imaging. Only two patients had grade IV cataract. In other words, we had homogenous data as regard to cataract hardness. This limitation has prevented us to detect increase in choroid thickness which may result from higher ultrasonic phaco power and longer surgical time generally required for dense brunescent cataract, putting the patient at higher risk of complications.

In our study, intraocular pressure decreased after cataract surgery. It is comparable to results of study conducted by Ohsugi et al who also concluded choroid thickness changes negatively correlated with intraocular pressure early after surgery. Another study conducted by Bayhan et al also had similar results ${ }^{6}$.

Many factors have been taken into account to understand the mechanism of decrease in intraocular pressure. Extraction of thick ocular lens with cataract widens anterior chamber angle, thus removing blockage and improving aqueous outflow, consequently decreasing intraocular pressure. Although our study shared correlation between changes in choroidal thickness and intraocular pressure in early post-operative, we believe that this will be worth confirming in study with longer post-operative duration. Ocular perfusion pressure is main driving force for ocular blood flow. Reduced intraocular pressure causes increased ocular perfusion that increase choroidal thickness as choroid is rich vascular tissue. Increased SFCT as measured by SD-OCT in our study is indicative of increased choroidal perfusion caused by reduced intraocular pressure in early post-operative period after cataract surgery.

\section{CONCLUSION}

Choroidal thickness is significantly increased after cataract surgery. It is correlated with decreased intraocular pressure in early post-operative period. In regular practice, post-surgical inflammatory insult is managed with topical NSAIDs. However, even with this standard practice surgery still induced changes in choroidal thickness. This is especially significant for understanding pathogenesis of retinal and choroidal changes after phacoemulsification such as pseudophakic cystoid macular edema.

\section{Conflict of Interest: None.}

\section{Authors' Contribution}

AR: Direct, OZ: Direct contribution to conception/ supervision, SK: Intellectual/analysis, HJ: Data collection.

\section{REFERENCES}

1. Nikkhah H, Feizi M, Abedi N, Karimi S, Yaseri M, Esfandiari H. Choroidal Thickness in Acute Non-arteritic Anterior Ischemic Optic Neuropathy. J Ophthalmic Vis Res 2020; 15(1): 59-68. 


\section{Uneventful Phacoemulsification Surgery}

2. Breher K, Ohlendorf A, Wahl S. A metrological approach to the analysis of choroidal thickness by optical coherence tomography 3D scans in myopia research. Sci Rep 2019; 9(1): 20322.

3. Steiner M, Esteban-Ortega, Muñoz-Fernández S. Choroidal and retinal thickness in systemic autoimmune and inflammatory diseases: A review. Surv Ophthalmol 2019; 64(6): 757-769.

4. Gomi F, Tano Y. Polypoidal choroidal vasculopathy and treatments. Curr Opin Ophthalmol 2008; 19(3): 208-212.

5. Kılıç R, Kurt A, Acer E, Öktem Ç, Kocamış Ö. Choroidalthickness in psoriasis. Int Ophthalmol 2017; 37(1): 173-177.

6. Bayhan SA, Bayhan HA, Muhafiz E, Kırboğa K, Gürdal C. Evaluation of choroidal thickness changes after phacoemulsifi-cation surgery. Clin Ophthalmol 2016; 10(1): 961-967.

7. Hendrick AM, Gibson MV, Kulshreshtha A. Diabetic Retinopathy. Prim Care 2015; 42(3): 451-464.

8. Sharma N, Singhal D, Nair PS, Sahay S, SS Sreeshankar, Maharana PK. Corneal edema after phacoemulsification. Ind J Ophthalmol 2017; 65(12): 1381-1389

9. Anderson DH, Mullins RF, Hageman GS, Johnson LV. A role for local inflammation in the formation of drusen in the aging eye. Am J Ophthalmol 2002; 134(3): 411-431.

10. Jaffe GJ, Caprioli J. Optical coherence tomography to detect and manage retinal disease and glaucoma. Am J Ophthalmol 2004; 137(1): 156-169.

11. Abd El-Mawgoud S, Arfeen S, El-Gendy N, Fathy A. Early changes of choroidal and macular thickness after uneventful phacoemulsification surgery. Delta J Ophthalmol 2018: 19(2): 106-110

12. Gali HE, Sella R, Afshari NA. Cataract grading systems: a review of past and present. Curr Opin Ophthalmol 2019; 30(1): 13-18.

13. Noda $Y$, Ogawa A, Toyama T, Ueta T. Long-term increase in subfoveal choroidal thickness after surgery for senile cataracts. Am J Ophthalmol 2014; 158(3): 455-459.
14. Yoon DH, Kang DJ, Kim MJ, Kim HK. New observation of microcystic macular edema as a mild form of cystoid macular lesions after standard phacoemulsification: Prevalence and risk factors. Med 2018; 97(15): e0355.

15. Ibrahim AM, Elgouhary SM, Nassar MK, El Batanony AH. Changes in choroidal thickness after cataract surgery. Semin Ophthalmol 2018; 33(5): 664-670.

16. Zeng S, Liang C, He Y, Chen Y, Zhao Q, Dai S, et al. Changes of Subfoveal Choroidal Thickness after Cataract Surgery: A MetaAnalysis. J Ophthalmol 2018; 2018(2): 2501325.

17. Morin AP, Gastaud P, Gostoli SB. Measurement of subfoveal choroidal thickness before and after cataract surgery using enhanced depth imaging spectral domain optical coherence tomography. Invest Ophthalmol Vis Sci 2012; 53(14): 2125.

18. Torabi H, Sadraei M, Jadidi K, Alishiri AA. Choroidal thickness changes following cataract surgery in patients with type 2 diabetes mellitus. J Curr Ophthalmol 2018; 31(1): 49-54.

19. Xu H, Chen M, Forrester JV, Lois N. Cataract surgery induces retinal pro-inflammatory gene expression and protein secretion. Invest Ophthalmol Vis Sci 2011; 52(1): 249-255.

20. Jiang J, Shihan MH, Wang Y, Duncan MK. Lens Epithelial Cells Initiate an Inflammatory Response Following Cataract Surgery. Invest Ophthalmol Vis Sci 2018; 59(12): 4986-4997.

21. Tso MO, Shih CY. Experimental macular edema after lens extraction. Invest Ophthalmol Vis Sci 1977; 16(5): 381-392.

22. Ikegami Y, Takahashi M, Amino, K. Evaluation of choroidal thickness, macular thickness, and aqueous flare after cataract surgery in patients with and without diabetes: a prospective randomized study. BMC Ophthalmol 2020; 20(2): 102.

23. Hideharu $\mathrm{O}$, Yasushi I, Zaigen $\mathrm{O}$. Changes in choroidal thickness after cataract surgery. J Cataract Refrac Surg 2014: 40(2): 184-191. 